\title{
Termination of nanoscale zero-valent iron reactivity by addition of bromate as a reducing reactivity competitor
}

Mines, Paul D.; Kaarsholm, Kamilla Marie Speht; Droumpali, Ariadni; Andersen, Henrik Rasmus; Lee, Wontae; Hwang, Yuhoon

Published in:

Journal of Nanoparticle Research

Link to article, DOI:

10.1007/s11051-017-4000-x

Publication date:

2017

Document Version

Peer reviewed version

Link back to DTU Orbit

Citation (APA):

Mines, P. D., Kaarsholm, K. M. S., Droumpali, A., Andersen, H. R., Lee, W., \& Hwang, Y. (2017). Termination of nanoscale zero-valent iron reactivity by addition of bromate as a reducing reactivity competitor. Journal of Nanoparticle Research, 19(9), [301]. https://doi.org/10.1007/s11051-017-4000-x

\section{General rights}

Copyright and moral rights for the publications made accessible in the public portal are retained by the authors and/or other copyright owners and it is a condition of accessing publications that users recognise and abide by the legal requirements associated with these rights.

- Users may download and print one copy of any publication from the public portal for the purpose of private study or research.

- You may not further distribute the material or use it for any profit-making activity or commercial gain

- You may freely distribute the URL identifying the publication in the public portal 


\title{
Termination of nanoscale zero-valent iron reactivity by addition of bromate as a reducing reactivity competitor
}

\author{
Paul D. Mines ${ }^{\mathrm{a}, \mathrm{b}}$, Kamilla M.S. Kaarsholm ${ }^{\mathrm{a}}$, Ariadni Droumpali ${ }^{\mathrm{a}}$, Henrik R. Andersen ${ }^{\mathrm{a}}$, \\ Wontae Lee ${ }^{\mathrm{c}}$, and Yuhoon Hwang ${ }^{\mathrm{d}^{*}}$
}

${ }^{a}$ Department of Environmental Engineering, Technical University of Denmark, Bygningstorvet. B115, DK-2800 Kongens Lyngby, Denmark

${ }^{\mathrm{b}}$ Department of Micro- and Nanotechnology, Technical University of Denmark, Ørsteds Plads, B345C, DK-2800 Kongens Lyngby, Denmark

c Department of Environmental Engineering, Kumoh National Institute of Technology, 61 Daehak-ro, Gumi, Gyeongbuk 39177, Republic of Korea

d Department of Environmental Engineering, Seoul National University of Science and Technology, 232 Gongneung-ro, Nowon-gu, Seoul 01811, Republic of Korea

\begin{abstract}
Remediation of contaminated groundwater by nanoscale zero-valent iron (nZVI) is widely becoming a leading environmentally-friendly solution throughout the globe. Since a wide range of various nZVI-containing materials have been developed for effective remediation, it is necessary to determine an appropriate way to terminate the reactivity of any nZVIcontaining material for a practical experimental procedure. In this study, bimetallic Ni/FeNPs were prepared to enhance overall reduction kinetics owing to the catalytic reactivity of nickel on the surface of nZVI. We have tested several chemical strategies in order to terminate nZVI reactivity without altering the concentration of volatile compounds in the solution. The strategies include surface passivation in alkaline conditions by addition of carbonate, and consumption of nZVI by a reaction competitor. Four halogenated chemicals, trichloroethylene, 1,1,1-trichloroethane, atrazine, and 4-chlorophenol were selected and tested as model groundwater contaminants. Addition of carbonate to passivate the nZVI surface was not effective for trichloroethylene. Nitrate and then bromate were applied to competitively consume nZVI by their faster reduction kinetics. Bromate proved to be more effective than nitrate, subsequently terminating nZVI reactivity for all four of the tested halogenated compounds. Furthermore, the suggested termination method using bromate was successfully applied to obtain trichloroethylene reduction kinetics. Herein, we report the simple and effective method to terminate the reactivity of nZVI by addition of a reducing reactivity competitor.
\end{abstract}

\section{Keywords}

nZVI, reactivity termination, bromate, groundwater remediation

\section{Introduction}

Contamination of soils and groundwater poses a significant risk to human health and results

\footnotetext{
* Corresponding authors
}

\section{Dr. Yuhoon Hwang}

E-mail:yhhwang@seoultech.ac.kr, Tel: +82-2-970-6626, Fax: +82-2-971-5776 
in numerous negative consequences related to food, fodder, and water for drinking and irrigation. Pollutants causing these harmful effects towards humans can range from chlorinated hydrocarbons (Badawi et al. 2000), to polycyclic aromatic hydrocarbons (Zhang et al. 2005), to metals and metalloids (McIntyre 2003), among others. Including these compounds, as well as many others, a recent survey determined that there are approximately 1,170,000 potentially contaminated sites in Europe, with at least 127,000 identified or confirmed (Panagos et al. 2013). More specifically with groundwater sites though, an older estimate put the number at 20,000 contaminated sites needing to be remediated in Europe alone, with potentially 350,000 more sites yet to be identified (Prokop et al. 2000). Furthermore, Panagos et al. report that of all the contaminants affecting groundwater, approximately $10 \%$ if those contain harmful chlorinated hydrocarbons, which include compounds such as trichloroethylene (TCE), 1,1,1-trichlorethane (TCA), and many others (Panagos et al. 2013).

Nanoscale zero-valent iron (nZVI) is a promising reactive medium for rapid in situ remediation of various contaminants, including chlorinated solvents, in the groundwater and soil. Its standard redox potential $\left(\mathrm{E}_{0}=-0.44 \mathrm{~V}\right)$ makes nZVI an effective material when reacting with reducible contaminants (Tosco et al. 2014). Moreover, surface modification of nZVI has been intentionally performed, in order to enhance the physical and reactive properties of nZVI that are desirable for environmental remediation. Especially, bimetallic particles having iron as the primary metal with the deposition of a thin layer of noble or transition metals, such as palladium $(\mathrm{Pd})$, copper $(\mathrm{Cu})$, nickel $(\mathrm{Ni})$ or platinum $(\mathrm{Pt})$, on the iron surface has been frequently applied to enhance the reactivity of nZVI (Ghauch and Tuqan 2008; Barnes et al. 2010)

Since the first documented case of nZVI being used to address groundwater contamination in the year 2000 at Trenton, New Jersey, USA, until 2013, globally over 70 remediation projects have been documented at either the pilot or full-scale operation. Most such deployments of nZVI have focused on the degradation of chlorinated solvents for plume (i.e. pathway) management in the subsurface (Bardos and Jones 2015).Characterizing the fate, transport, and effects of nZVI during groundwater remediation is complicated because of the complex interactions between the contaminant of concern, the surrounding environmental conditions, and the nZVI materials (e.g., suspensions of highly reactive and variably aggregated nanoparticles) (Li et al. 2006; Shi et al. 2015; Zou et al. 2016). Often times, especially when working in the field, measurements cannot immediately take place. This lag in the time from sample collection to sample measurement can potentially change the constituents present in a given sample, possibly from various chemical oxidation or reduction processes, or even from biological processes. Depending on the situation, one cannot be entirely certain that all effecting mechanisms are rendered inert, even if the sample is filtered for example. To make the analysis of nZVI reactivity more user-friendly, an appropriate technique to immediately terminate the reactivity in the sample is ideal; allowing for analysis at the technician's convenience.

Termination of nZVI can be performed in two approaches. At first, physical separation of nZVI from reaction medium can be considered. As described in our previous research on the development of a colorimetric assay for nZVI reactivity (Hwang et al. 2016) and work using nZVI impregnated into porous polymer matrices for groundwater remediation (Mines et al. 2016), termination of nZVI reactivity has been performed by using membrane filtration to separate out nZVI from the bulk reaction solution. However, filtration cannot be used for 
volatile compounds, since they can be volatilized during the filtration step. Another option could be centrifugation, but this approach could require a lengthy amount of time for complete sedimentation/pelletization in the case of stabilized nZVIs with polymers, for example. Moreover, the reaction can also actively take place at the bottom of a reaction vessel in the filtrate or pellet. Therefore, it is required to determine a methodology to terminate the reactivity of nZVI, without altering the concentration of volatile or non-volatile compounds in the solution.

Since physical separation cannot be the ideal solution for many cases, a chemical approach to terminate the reactivity of nZVI may be considered. The effect of reaction conditions on nZVI reactivity has been intensively studied through reaction kinetics; investigating for example, the effects of pH (Liu and Lowry 2006) or competing water solutes (Liu et al. 2007). In most cases, it was known that a low $\mathrm{pH}$ is favorable for nZVI technology because of the greater availability of electrons from the $\mathrm{Fe}^{0}$ core, due to a more rapid dissolution of the surrounding oxide layer (O'Carroll et al. 2013). The reaction kinetics generally slow down at higher $\mathrm{pH}$ values, due to passivation of the nZVI surfaces by the precipitation of iron oxides and hydroxides (Bae and Lee 2010). Several water solutes may act competitively as electron acceptors (Kim et al. 2013) or may precipitate on the nZVI surface, which ultimately result in a passivation of the nZVI surface (Chen et al. 2011a). However, those previous studies only focused on determining suitable conditions for contaminant removal, as opposed to terminating nZVI reactivity for practical experimental purposes.

In this study, we have tested several strategies to terminate nZVI reactivity without altering the concentration of volatile compounds in the solution. Laboratory-synthesized bimetallic $\mathrm{Ni} / \mathrm{Fe}-\mathrm{NPs}$ were used as the model nZVI tested in this study to enhance overall reaction kinetics. The strategies include surface passivation in alkaline conditions by addition of carbonate, and consumption of nZVI by a reaction competitor. Four halogenated chemicals, trichloroethylene, 1,1,1-trichloroethane, atrazine, and 4-chlorophenol were selected and tested as model groundwater contaminants. Moreover, the selected termination method was tested to obtain reaction kinetics, in order to show its practical applicability for extracted samples in the laboratory or field monitoring station.

\section{Materials and Methods}

\subsection{Chemicals}

The detailed information about chemicals used for the study is described in supplementary information S1.

\subsection{Preparation of bimetallic Ni/Fe-NPs}

The preparation of nZVI for this study utilized the mild chemical reduction of metals salts in the solution phase, as was used in a previous study analyzing washing and storage strategies for nZVI (Hwang et al. 2014):

$$
2 \mathrm{Fe}^{2+}+\mathrm{BH}_{4}^{-}+3 \mathrm{H}_{2} \mathrm{O} \rightarrow \mathrm{H}_{2} \mathrm{BO}_{3}^{-}+4 \mathrm{H}^{+}+2 \mathrm{H}_{2} \uparrow
$$

The synthesis was conducted in a $1000 \mathrm{~mL}$ three-neck round-bottom flask reactor, with the central neck fitted with a tunable mechanical stirrer capable of 40 - 2000 RPM (RZR2021, Heidolph, Germany); the two remaining necks were sealed with rubber septa. The stirring speed was adjusted to 250 RPM for the synthesis of the nZVI, and lowered to 100 RPM for the subsequent aging of the nZVI. Iron precursor solution was prepared with $600 \mathrm{~mL}$ of 0.24 
$\mathrm{M} \mathrm{FeSO}_{4} \cdot 7 \mathrm{H}_{2} \mathrm{O}$ in deionized water. The reduction of the iron was initiated by introducing $200 \mathrm{~mL}$ of $1.8 \mathrm{M} \mathrm{NaBH}_{4}$ solution in deionized water via peristaltic pump, with a constant delivery rate of $10 \mathrm{~mL} / \mathrm{min}$. The black precipitate was further aged for 30 min after $\mathrm{NaBH}_{4}$ injection. Collection and washing of the nZVI was performed via centrifugation (2500 RPM, 5 min, Heraeus Multifuge X1, Thermo Scientific, USA), and the collected pellet of nZVI was then washed with deionized water and twice with ethanol, interspersed with centrifugation. Once washed, the nZVI particles were dried in a vacuum oven at $60{ }^{\circ} \mathrm{C}$ for $4 \mathrm{~h}$ and subsequently stored in air-tight vials inside an anaerobic chamber $\left(\mathrm{N}_{2}: \mathrm{H}_{2}=95: 5\right.$, Coy Laboratory Products, USA), to avoid any oxidation. The physical characteristics of the prepared nZVI are considered to be identical to uncoated nZVI prepared in the previously mentioned study (Hwang et al. 2014), as the same synthesis protocol was used.

Ni-doped bimetallic nZVI particles (Ni/Fe-NPs) were prepared via chemical reduction, as presented in the previously mentioned study (Hwang et al. 2016). The secondary metal solution $\left(\mathrm{NiSO}_{4}\right)$ was introduced to the nZVI particles, whereupon bimetallic $\mathrm{Ni} / \mathrm{Fe}$ is spontaneously produced by the attachment of nickel on the iron surface. The mixture placed in a sonication bath for $3 \mathrm{~min}$, followed by $10 \mathrm{~min}$ of vortex mixing, in order to completely disperse the particles and eliminate any aggregates that may have been formed. All mixing was conducted in an anaerobic chamber, and the vials were capped securely with a PTFE/silicon setpum and aluminum crimp seal, to avoid any oxidation. After 10 min of redox reaction between the nickel and the nZVI, the resulting Ni/Fe-NPs were collected and washed twice with deionized water and centrifugation (as mentioned above). Prepared Ni/Fe-NPs were immediately applied in the reactivity tests; therefore, further drying was not needed or considered.

\subsection{Characterization of $\mathrm{Ni} / \mathrm{Fe}$ nanoparticles (Ni/Fe-NPs)}

Surface imaging and morphology of the prepared Ni/Fe-NPs was performed using field emission - transmission electron microscopy (FE-TEM, FEI, Tecnai T20 G ${ }^{2}$, The Netherlands). Additionally, elemental mapping of the particles was performed using the scanning transmission electron microscopy feature on the TEM instrument, coupled with energy dispersive X-ray spectroscopy (STEM-EDS). Data treatment for the STEM-EDS was analyzed with Aztec software (Oxford Instruments, United Kingdom). TEM analysis was conducted by sonicating and applying a droplet of Ni/Fe-NPs suspended in ethanol on to a carbon-coated copper mesh grid (300-mesh, FCF300-Cu Formvar Carbon Film, Electron Microscopy Sciences, USA).

\subsection{Reactivity Test}

Reactivity of bimetallic Ni/Fe-NPs were tested with various groundwater contaminants, trichloroethylene (TCE), 1,1,1-trichloroethane (TCA), atrazine, and 4-chlorophenol. It has been determined that a bimetallic nZVI particles with a nickel concentration (wt:wt) of $5 \%$ is more than enough to dehalogenate certain halogenated organics (Hwang et al. 2015; Hwang et al. 2016); therefore, all reactivity termination tests were conducted with this particular Ni:Fe ratio.

As prepared solutions of Ni/Fe-NPs, as mentioned in Section 2.2, were re-suspended in 50 $\mathrm{mL}$ of fresh deionized water, along with three glass beads (diameter $=4 \mathrm{~mm}$ ) to ensure turbulent conditions and adequate mixing during reactivity testing. The concentration of bimetallic Ni/Fe-NPs was determined as $2 \mathrm{~g} / \mathrm{L}$. The vials were then immediately spiked with stock solutions of TCE, TCA, atrazine, or 4-chlorophenol (in separate vials). In order to 
simulate realistic conditions, a concentration of $300 \mu \mathrm{g} / \mathrm{L}$ of TCE and TCA was assessed, as that is slightly higher than reported values (i.e. $~ 250 \mu \mathrm{g} / \mathrm{L}$ ) for TCE detected in Danish groundwater (McKnight et al. 2010). In the case of 4-chlorophenol, the initial concentration was determined to be $500 \mu \mathrm{M}$, which is identical to the previously mentioned study regarding the colorimetric assay (Hwang et al., 2016). Initial atrazine concentration was determined to be $120 \mu \mathrm{g} / \mathrm{L}$, as that concentration is slightly higher than values (i.e. 100 $\mu \mathrm{g} / \mathrm{L}$ ) observed in the past for various river waters in the USA (Squillace et al. 1993).

\subsection{Terminating dehalogenation reactivity of $\mathrm{nZVI}$}

\subsubsection{Formation of passivating layer - carbonate}

Carbonate, added as $\mathrm{Na}_{2} \mathrm{CO}_{3}$, was firstly chosen for terminating dehalogenation reactivity of nZVI. The applied carbonate concentration was determined as $50 \mathrm{mM}$, in order to have stoichiometrically more carbonate than needed for complete reaction with the nZVI concentration of $35.8 \mathrm{mM}$ in the reactor. The dehalogenation reactivity of nZVI was determined by the reaction with TCE and 4-chlorophenol.

In order to distinguish the effect of carbonate addition, a pre-addition and a post-addition scheme was applied. The pre-addition scheme was performed to determine the effectiveness of the terminating agent, carbonate. Concentrated carbonate stock solution (i.e. $2 \mathrm{M}$ ) was added prior to halogenated compound addition, therefore, nZVI could be allowed to react with carbonate first, leading to deactivation and passivation.

At the same time, post-addition of carbonate after 30 minutes of reaction time was performed to obtain the dehalogenation reactivity of nZVI. By allowing the nZVI to be in contact with the contaminant for 30 minutes before exposure to carbonate, the dehalogenation reactivity can be determined. Moreover, a control experiment without nZVI addition was also performed in order to quantify the initial concentration of the halogenated compounds.

The reaction vials were placed on a rotary mixer and allowed to react for 30 minutes. After the reaction, the concentrations of TCE and 4-chlorophenol were measured immediately as mentioned in the following Section 2.6.

\subsubsection{Reducing reactivity competitors - nitrate and bromate}

The reducing reactivity competitors, nitrate, added as $\mathrm{NaNO}_{3}$, and bromate, added as $\mathrm{NaBrO}_{3}$, were separately added into the carbonate solution already described in Section 2.5.1 to provide a measurement of the compound's ability to consume unreacted nZVI. The concentrations of nitrate and bromate were determined to be double the stoichiometric amount needed for complete reaction with the nZVI in the reactor; therefore, $17.9 \mathrm{mM}$ for nitrate and $23.9 \mathrm{mM}$ for bromate.

The pre-addition, post-addition, and control experiments were performed in the same manner as with the carbonate addition described in Section 2.5.1. Initially, the two halogenated compounds tested with nitrate and bromate addition were TCE and 4-chlorophenol, the same as was used with carbonate addition. After bromate showed successful results for TCE and 4chlorophenol, the additional halogenated compounds of TCA and atrazine were tested for further confirmation of the applicability of bromate.

\subsection{Analysis}

\subsubsection{Trichloroethylene (TCE) and 1,1,1,-trichloroethane (TCA)}

Samples were analyzed for TCE and TCA using the purge-and-trap technique coupled with 
gas chromatography - mass spectrometry. The detailed conditions are given in supplementary information S2.

\subsubsection{Atrazine}

Samples were analyzed for atrazine using high performance liquid chromatography. The detailed conditions are given in supplementary information S3.

\subsubsection{4-chlorophenol}

In order to obtain the 4-chlorophenol concentration in the reaction vials, the reaction product, phenol, was measured by the colorimetric assay developed in our previous study (Hwang et al. 2015). The detailed conditions are given in supplementary information S4.

\section{Results and Discussion}

\subsection{Morphology of prepared bimetallic Ni/Fe-NPs}

The morphologies of the Ni/Fe-NPs prepared in this study were observed using transmission electron microscopy (TEM) and are pictured in Figure 1-A and 1-B with different magnifications. The Ni/Fe-NPs were spherical and were aggregated together in a chain-like network . This spherical shape, chain net morphology, and appearance of the iron-oxide shell surrounding the nZVI core were similar to those observed in other research works (Wang et al. 2006; Nadagouda et al. 2010; Ryu et al. 2011) studying nZVI particles. Particle sizes ranged in diameters between 25 to $250 \mathrm{~nm}$, with the bulk of the particles falling in the $50-150 \mathrm{~nm}$ range. The bulk of the Ni/Fe-NPs also possessed an iron-oxide shell with thicknesses ranging from 2 to $8 \mathrm{~nm}$. Determination of nickel on the nZVI surface is extremely difficult with normal observation with TEM, therefore scanning-TEM coupled with energy dispersive Xray spectroscopy (STEM-EDS) was employed to visually identify "islands" of nickel found on the surface of the nZVI. Although the quality of the image decreases when using STEM, it is clearly visible with the EDS coupling that islands of nickel do appear on the surface of the particles, pictured in Figure 1-C (STEM) and 1-D (STEM-EDS). 

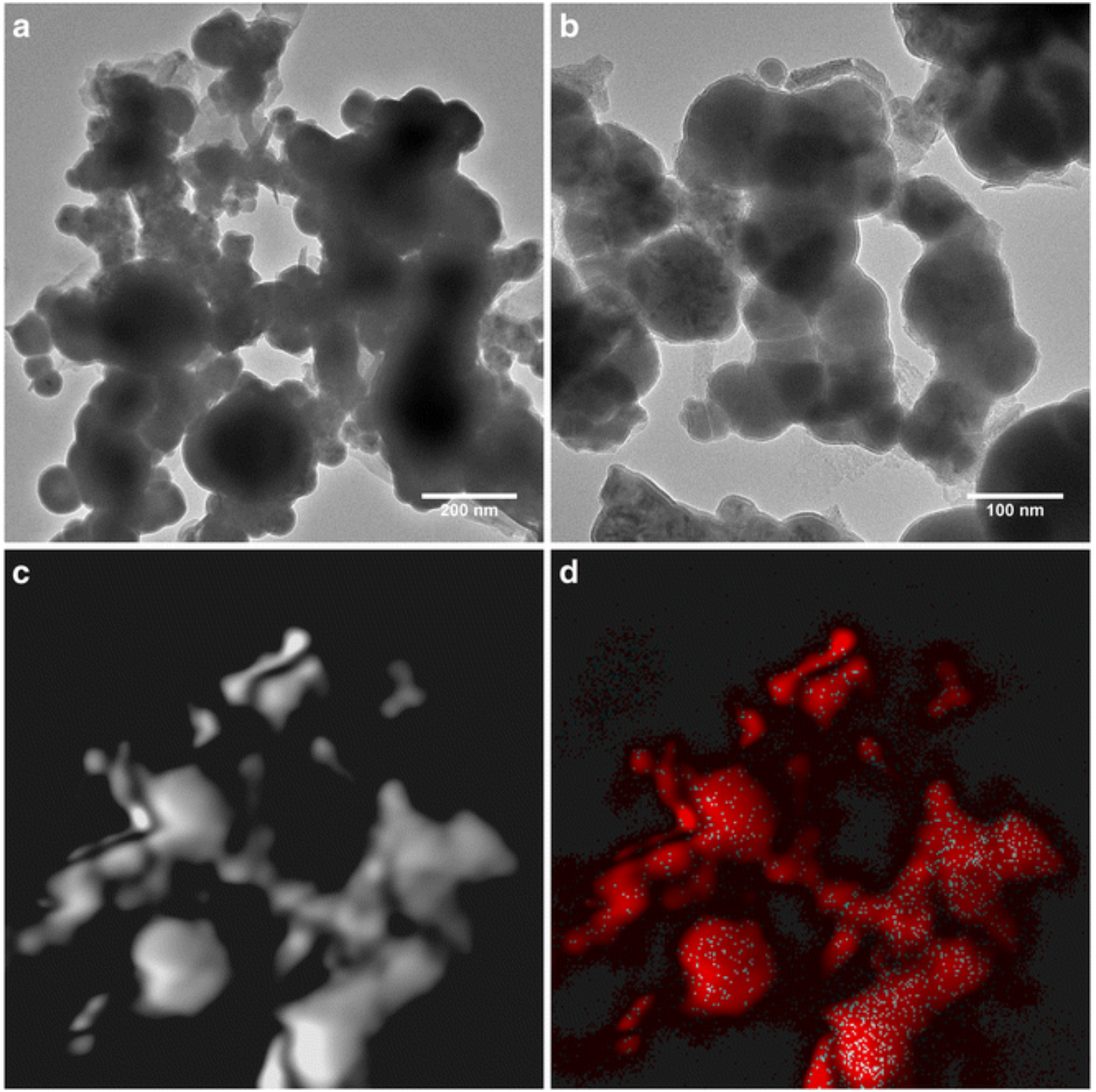

Fig. 1 Electron microscope imaging of Ni/Fe-NPs: A) TEM at lower magnification; B) TEM at higher magnification; C) STEM of image in A; and D) STEM-EDS mapping of image in A with iron (visualized in red) as the dominant species with "islands" of nickel (visualized in blue) blanketing the particles. Note: STEM imaging requires rotation of the sample in the instrument $45^{\circ}$ clockwise.

\subsection{Precipitation by addition of sodium carbonate}

The initial attempt at terminating the reactivity of Ni/Fe-NPs assumed that all that was necessary for termination was to precipitate the particles out of solution. This way, the remaining supernatant was free of reactive iron. As zero-valent iron reduces different contaminants, it itself becomes oxidized from contaminant reduction, water, and the dissolved oxygen in water. In this process, ferrous $\left(\mathrm{Fe}^{2+}\right)$ iron is formed. Carbonate $\left(\mathrm{CO}_{3}{ }^{2-}\right)$ is a well-known precipitant, and is commonly applied to ferrous iron for this purpose; the result is a rapidly settled green precipitate, which is outlined below in Eqs. 2 and 3 (using water as the oxidizer) (Mackenzie et al. 1999).

$$
\begin{gathered}
\mathrm{Fe}^{0}+2 \mathrm{H}_{2} \mathrm{O} \rightarrow \mathrm{Fe}^{2+}+\mathrm{H}_{2} \uparrow+2 \mathrm{OH}^{-} \\
\mathrm{Fe}^{2+}+\mathrm{CO}_{3}^{2-} \rightarrow \mathrm{FeCO}_{3}(\mathrm{~s})
\end{gathered}
$$


The assumption is that in the presence of carbonate, any ionic ferrous iron or remaining exposed $\mathrm{Fe}^{0}$ would form $\mathrm{FeCO}_{3}$ or $\mathrm{Fe}(\mathrm{OH})_{2}$ as particulates or as a shell around nZVI that would act as a passivating layer (Nurmi and Tratnyek 2008). We have tested this assumption with two model halogenated contaminants, TCE and 4-chlorophenol (4-CP).

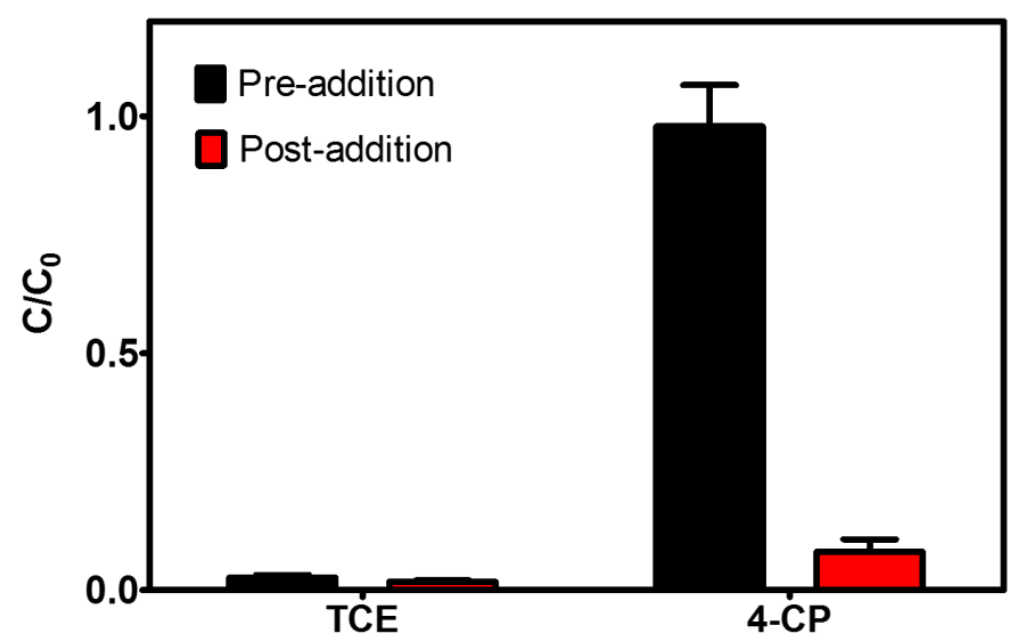

Fig. 2 Effect of carbonate for the termination of nZVI's reactivity $\left(C_{0, ~ T C E}=300 \mu \mathrm{g} / \mathrm{L}, \mathrm{C}_{0,4-\mathrm{CP}}=500 \mu \mathrm{M}\right.$, $\left.\mathrm{C}_{\mathrm{Ni} / \mathrm{Fe}-\mathrm{NPs}}=2 \mathrm{~g} / \mathrm{L}, \mathrm{C}_{\mathrm{CO} 3}=50 \mathrm{mM}\right)$. Error bars indicate standard deviation based on triplicates.

Figure 2 presents the effectiveness of carbonate addition $(50 \mathrm{mM})$ for the termination of nZVI reactivity. When bimetallic Ni/Fe-NPs (2 g/L; $5 \% \mathrm{Ni}$ ) were allowed to react with 300 $\mu \mathrm{g} / \mathrm{L}$ of TCE solution for $30 \mathrm{~min}$, there was nearly no difference whether or not carbonate was present in the solution. TCE reduction after $30 \mathrm{~min}$ of reaction was $98.1 \%$ with the case of carbonate post-addition, meaning there was no carbonate present during the reaction with TCE. Concurrently, there was a similar reduction in TCE, 97.3\% after 30 min of reaction, with the case of carbonate pre-addition, meaning carbonate was present during the reaction with TCE. The most likely explanation is that although there are precipitates and oxide shells being formed, the bimetallic Ni/Fe-NPs are not fully forming a complete passivation layer on the surface, allowing for continued electron transfer and subsequent reactivity to take place.

Using the same experimental design, 4-chlorophenol was also assessed as the target compound for reduction by $\mathrm{Ni} / \mathrm{Fe}-\mathrm{NPs}$. However, it was observed that 4-chlorophenol reduction was much more sensitive to the presence of carbonate in solution. Where, $91.9 \%$ of 4-chlorophenol could be reduced in the absence of carbonate (i.e. post-addition); while, only $2.1 \%$ of 4-chlorophenol was reduced in the presence of carbonate (i.e. pre-addition). This means that nZVI reactivity towards 4-chlorophenol reduction is, for the most part, successfully terminated by the addition of carbonate. Furthermore, in order to investigate the effect of carbonate addition on 4-chlorophenol reduction by Ni-Fe-NPs in more detail, kinetics curves were obtained up to $120 \mathrm{~min}$ of reaction time. (Figure S1).

When analyzing the kinetics of the reaction, it was found that the Ni/Fe-NPs were capable of completely reducing $500 \mu \mathrm{M}$ of 4-chlorophenol within an hour when no carbonate was present. Using pseudo first-order kinetics, the rate constant was determined to be $\mathrm{k}=$ $0.007946 \mathrm{~min}^{-1}$. On the other hand, a much slower reduction of 4-chlorophenol was observed when carbonate was added before the reaction; however, it did not completely terminate the particles' reactivity. In the same time frame of one hour, only $12.7 \%$ of the 4 -chlorophenol 
was reduced to phenol, although the reduction exhibited near-linear kinetics with a rate constant of $\mathrm{k}=0.0002503 \mathrm{~min}^{-1}$. This means that carbonate is capable of inhibiting the reduction reaction, but it cannot fully consume nZVI's reactivity based on this inhibition mechanism. Rather, the carbonate creates a passivation layer on the surface of the particles; however, this passivation layer does not form an impenetrable ubiquitous barrier over all of the nZVI surface and/or can possibly act as an electron conductive material to some degree (Theron et al. 2008). Therefore, a slow release of electrons could take place, bringing about a gradual reduction of 4-chlorophenol. So, it is apparent that merely applying a precipitation and passivation mechanism towards bimetallic Ni/Fe-NPs is not enough to terminate the reactivity sufficiently.

\subsection{Addition of nitrate as a reduction competitor}

It is widely known that nitrate can react with nZVI and be reduced to ammonium (Hwang et al. 2011), see Equation 4; and, if the kinetics of reduction are compared when assessing nZVI reactivity towards nitrate (Hwang et al. 2011) vs. 4-chlorophenol (Hwang et al. 2015), it is apparent that nitrate reduction by nZVI is significantly faster than 4-chlorophenol dehalogenation to phenol.

$$
4 \mathrm{Fe}^{0}+\mathrm{NO}_{3}^{-}+10 \mathrm{H}^{+} \rightarrow 4 \mathrm{Fe}^{2+}+\mathrm{NH}_{4}^{+}+3 \mathrm{H}_{2} \mathrm{O}
$$

Given that knowledge, it is theorized that there would be preferential reactivity of Ni/Fe-NPs with nitrate when in competition with another halogenated organic, such as TCE. In this light, adding an excess of nitrate solution is hypothesized to consume all available/remaining reactive sites on the $\mathrm{Ni} / \mathrm{Fe}-\mathrm{NPs}$ and terminate the reactivity, eliminating any subsequent interaction with TCE. Just as before, the effect of nitrate as a reaction inhibitor of Ni/Fe-NPs on halogenated contaminants (i.e, TCE and 4-chlorophenol) was examined using the preaddition and post-addition approach, Figure 3.

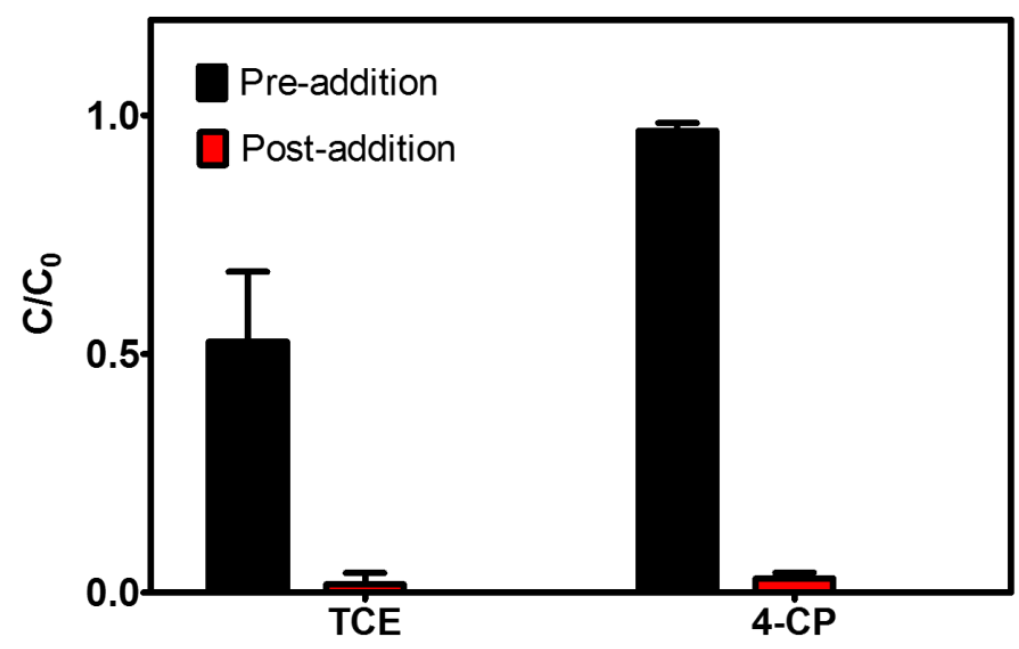

Fig. 3 Effect of nitrate for termination of nZVI's reducing activity $\left(C_{0, \mathrm{TCE}}=300 \mu \mathrm{g} / \mathrm{L}, \mathrm{C}_{0,4-\mathrm{CP}}=500 \mu \mathrm{M}\right.$, $\left.\mathrm{C}_{\mathrm{Ni} / \mathrm{Fe}-\mathrm{NPs}}=2 \mathrm{~g} / \mathrm{L}\right)$. Error bars indicate standard deviation based on triplicates.

Expectedly, adding the nitrate $(17.9 \mathrm{mM})$ to the solution of bimetallic Ni/Fe-NPs (2 g/L; $5 \%$ Ni) after the 30 min reaction time (i.e. post-addition) did nothing to terminate the reaction and nearly all of the halogenated compounds were removed (Figure 3, red bars). Whereas, initial addition of nitrate (i.e. pre-addition) inhibited approximately $47.4 \%$ of the Ni/Fe-NPs reactivity with TCE and approximately $96.7 \%$ of the Ni/Fe-NPs reactivity with 4chlorophenol (Figure 3, black bars). Being that carbonate proved to be effective at 
terminating the 4-chlorophenol dehalogenation to phenol, it is not surprising that by adding nitrate, similar results were obtained. While moderately effective in stopping the reduction of TCE, adding nitrate to terminate the reactivity is not complete, and therefore not an appropriate technique for reactivity termination.

\subsection{Addition of bromate as a reduction competitor}

Complete termination of the reaction using nitrate was unsuccessful; therefore a new technique had to be employed. Although not extensively studied, the reaction of bromate with nZVI has been performed and results indicate very fast reaction kinetics, with the proposed pathway detailed as follows in Equations 5-7 (Wang et al. 2009).

$$
\begin{aligned}
\mathrm{BrO}_{3}^{-}+3 \mathrm{Fe}^{0}+3 \mathrm{H}_{2} \mathrm{O} & \rightarrow \mathrm{Br}^{-}+3 \mathrm{Fe}^{2+}+6 \mathrm{OH}^{-} \\
\mathrm{BrO}_{3}^{-}+2 \mathrm{Fe}^{0}+3 \mathrm{H}_{2} \mathrm{O} & \rightarrow \mathrm{Br}^{-}+2 \mathrm{Fe}^{3+}+6 \mathrm{OH}^{-} \\
\mathrm{BrO}_{3}^{-}+6 \mathrm{Fe}^{2+}+3 \mathrm{H}_{2} \mathrm{O} & \rightarrow \mathrm{Br}^{-}+6 \mathrm{Fe}^{3+}+6 \mathrm{OH}^{-}
\end{aligned}
$$

This concept was applied to improve upon the mediocre results obtained from the addition of nitrate. At first, the same experimental design of reaction inhibitor pre-addition and postaddition, and reacting bimetallic Ni/Fe-NPs with only TCE and 4-chlorophenol was used, except with bromate rather than nitrate; and, the results were extremely positive. When using bromate to terminate the reaction, all of the initial TCE or 4-chlorophenol was detected after 30 minutes when adding it at the onset (i.e. pre-addition) of the reaction period (Figure 4). Concurrently, validation was again confirmed of the Ni/Fe-NPs reactivity towards TCE and 4-chlorophenol, in that when the bromate was added after the 30 minute reaction period (i.e. post-addition), nearly all of the contaminant was reduced.

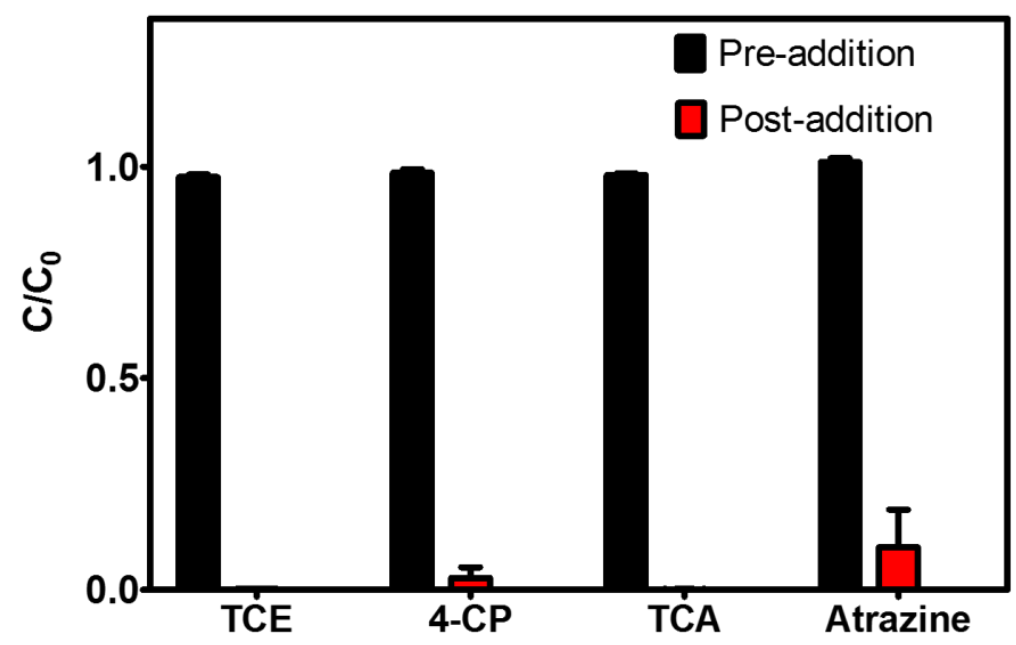

Fig. 4 Effect of nitrate for termination of nZVI's reducing activity $\left(C_{0, ~ T C E}=300 \mu \mathrm{g} / \mathrm{L}, \mathrm{C}_{0,4-\mathrm{CP}}=500 \mu \mathrm{M}\right.$, $\left.\mathrm{C}_{0, \mathrm{TCA}}=300 \mu \mathrm{g} / \mathrm{L}, \mathrm{C}_{0, \text { Atrazine }}=120 \mu \mathrm{g} / \mathrm{L}, \mathrm{C}_{\mathrm{Ni} / \mathrm{Fe}-\mathrm{NPs}}=2 \mathrm{~g} / \mathrm{L}\right)$. Error bars indicate standard deviation based on triplicates.

With this determined, the procedure was subsequently applied to both TCA and atrazine. Results for TCA and atrazine corresponded very closely to those of TCE and 4-chlorophenol, with the exception that the $\mathrm{Ni} / \mathrm{Fe}-\mathrm{NPs}$ were not always able to fully degrade the initial atrazine concentration with the 30 minute reaction period. Given these extremely successful results with the bromate addition, where the ideal outcome was achieved with merely a simple reagent addition, that one can terminate the sample reactivity; we have complete confidence that no matter when the ultimate analysis for reaction products is performed, it is 
indicative of the sample matrix at the time of sampling.

\subsection{Kinetic study using suggested termination method (bromate)}

In this study, we have suggested to use bromate to terminate the reactivity of nZVI by a simple injection of bromate solution into a reaction vial without altering the anoxic environment contained within. In order to confirm the applicability of this suggested method in practical experimental work, we have produced the kinetics curve for the reduction of TCE following the suggested method. In doing so, a number of vials were prepared containing 2 $\mathrm{g} / \mathrm{L}$ of $0.2 \%$ bimetallic Ni/Fe-NPs, $300 \mathrm{ug} / \mathrm{L}$ of TCE, allowing the solution to react, and then injecting the bromate solution at various desired time intervals up to $90 \mathrm{~min}$. At the conclusion of this reaction period, all of the pre-treated samples using bromate solution were measured by GC-MS (see Section 2.6.1), in order to determine the remaining TCE concentration. To clarify, this means that each sample has a different idling/waiting time until it is analyzed by GC-MS; therefore, the kinetic curves cannot be accurately obtained if the reaction is not successfully terminated.

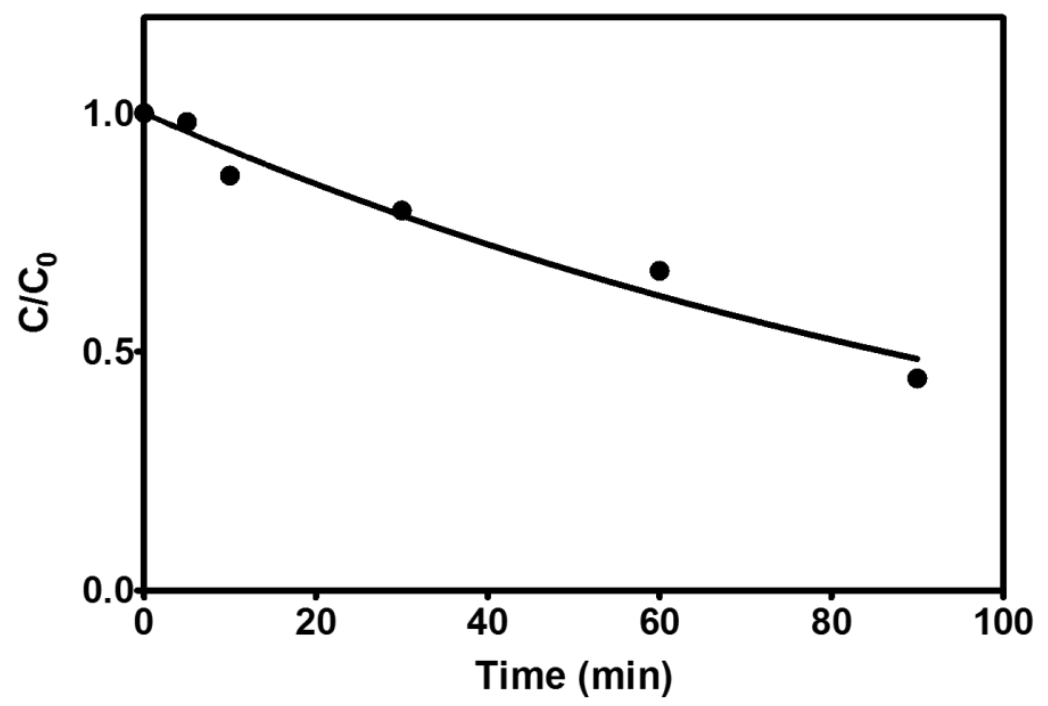

Fig. 5 TCE reduction kinetics obtained by the suggested bromate addition method for reaction termination $\left(\mathrm{C}_{0, \text { TCE}}=300 \mu \mathrm{g} / \mathrm{L}, \mathrm{C}_{\mathrm{Ni} / \mathrm{Fe}-\mathrm{NPs}(0.2 \%-\mathrm{Ni})}=2 \mathrm{~g} / \mathrm{L}\right)$.

The kinetics of TCE reduction obtained by the suggested bromate addition method for reaction termination are presented in Figure 5. In this case, bimetallic Ni-Fe-NPs with a markedly lower nickel content were applied, so that the reduction kinetics would slow down to a point where observation was easier and for simpler sample pre-treatment. The kinetics curve was successfully obtained and analyzed $\left(\mathrm{k}=0.00804 \mathrm{~min}^{-1}, \mathrm{R}^{2}=0.9646\right)$. It can be said with confidence that the work presented here has established, for the first time in reported literature, an appropriate method for terminating nZVI particle reactivity.

\section{Conclusions}

Even though there has been a great number of modified and unmodified nZVI's produced and applied for practical environmental remediation over the years, termination of the reactivity of nZVI as its applied has not been studied in detail or subsequently tested in the field or laboratory. We have examined several termination methods for this purpose, surface passivation by carbonate addition and consumption of unreacted nZVI by different reduction competitors; targeted at four commonly found halogenated compounds in the environment: 
trichloroethylene, 4-chlorophenol, 1,1,1-trichloroethane, and atrazine. When 5\% Ni/Fe bimetallic nZVI was used, all of these compounds could be effectively reduced in 30 minutes of reaction time. However, the dehalogenation reaction was not completely terminated by the addition of carbonate or nitrate. But, reactivity could be effectively terminated by the addition of bromate at twice the stoichiometric amount needed to react with the nZVI present. Bromate addition was effective for reaction termination in all of the tested compounds. The suggested method using bromate as a reduction competitor was then successfully applied to obtain the reduction kinetics curve of trichloroethylene, which then confirmed the applicability of this suggested method in real experimental work. In practical application, bromate should be added into the sample, either during lab experiments or from extracted samples when monitoring field treatments, to terminate the nZVI reaction with the contaminant. This way, the measured concentrations that are later analyzed correctly reflect the actual concentrations at the time of sampling.

\section{Acknowledgements}

P.D.M. and H.R.A. acknowledge funding for this study from the Technical University of Denmark (DTU) through the KAIST-DTU Signature Project on Integrated Water Technology. Y.H. acknowledges fundings for this study though a DFF-Individual Postdoctoral Grant from the Danish Council for Independent Research - Technology and Production Science (400500393B) and "The GAIA Project" by the Korea Ministry of Environment (RE201402059). W.L. acknowledges funding supported by Korea Ministry of Environment (MOE) as "GeoAdvanced Innovative Action” Program (Project No. 2015000560002). We would also like to thank Wilhelmus Huyzer from the DTU Center for Electron Nanoscopy (DTU-CEN) for his assistance with the nanoparticle characterization.

\section{Compliance with Ethical Standards}

Funding: This study was funded by the Technical University of Denmark (DTU) through the KAIST-DTU Signature Project on Integrated Water Technology, a DFF-Individual Postdoctoral Grant from the Danish Council for Independent Research - Technology and Production Science (4005-00393B), and “The GAIA Project” by the Korea Ministry of Environment (RE201402059, 2015000560002).

Conflict of Interest: The authors declare that they have no conflict of interest.

\section{References}

Badawi AF, Cavalieri EL, Rogan EG (2000) Effect of chlorinated hydrocarbons on expression of cytochrome P450 1A1, 1A2 and 1B1 and 2- and 4-hydroxylation of 17ßestradiol in female Sprague-Dawley rats. Carcinog 21:1593-1599.

Bae S, Lee W (2010) Inhibition of nZVI reactivity by magnetite during the reductive degradation of 1,1,1-TCA in nZVI/magnetite suspension. Appl Catal B Environ 96:1017. doi: 10.1016/j.apcatb.2010.01.028

Bardos P, Jones S (2015) Taking Nanotechnological Remediation Processes from Lab Scale to End User Applications for the Restoration of a Clean Environment (NanoRem) Project Nr.: 309517 EU, 7th FP, NMP.2012.1.2.

Barnes RJ, Riba O, Gardner MN, et al (2010) Optimization of nano-scale nickel/iron particles for the reduction of high concentration chlorinated aliphatic hydrocarbon solutions. Chemosphere 79:448-454. doi: http://dx.doi.org/10.1016/j.chemosphere.2010.01.044

Chen H, Luo H, Lan Y, et al (2011a) Removal of tetracycline from aqueous solutions using polyvinylpyrrolidone (PVP-K30) modified nanoscale zero valent iron. J Hazard Mater 192:44-53. doi: http://dx.doi.org/10.1016/j.jhazmat.2011.04.089 
Chen K-F, Li S, Zhang W (2011b) Renewable hydrogen generation by bimetallic zero valent iron nanoparticles. Chem Eng J 170:562-567. doi: http://dx.doi.org/10.1016/j.cej.2010.12.019

Ghauch A, Tuqan A (2008) Catalytic degradation of chlorothalonil in water using bimetallic iron-based $\quad$ systems. Chemosphere 73:751-759. doi: http://dx.doi.org/10.1016/j.chemosphere.2008.06.035

Hwang Y, Kim D-G, Shin H-S (2011) Mechanism study of nitrate reduction by nano zero valent iron. J Hazard Mater 185:1513-1521. doi: http://dx.doi.org/10.1016/j.jhazmat.2010.10.078

Hwang Y, Lee Y-C, Mines PD, et al (2014) Investigation of washing and storage strategy on aging of Mg-aminoclay (MgAC) coated nanoscale zero-valent iron (nZVI) particles. Chem Eng Sci 119:310-317. doi: 10.1016/j.ces.2014.08.002

Hwang Y, Mines PD, Jakobsen MH, Andersen HR (2015) Simple colorimetric assay for dehalogenation reactivity of nanoscale zero-valent iron using 4-chlorophenol. Appl Catal B Environ 166-167:18-24. doi: 10.1016/j.apcatb.2014.10.059

Hwang Y, Salatas A, Mines PD, et al (2016) Graduated characterization method using a multi-well microplate for reducing reactivity of nanoscale zero valent iron materials. Appl Catal B Environ 181:314-320. doi: 10.1016/j.apcatb.2015.07.041

Kim E-J, Murugesan K, Kim J-H, et al (2013) Remediation of Trichloroethylene by FeSCoated Iron Nanoparticles in Simulated and Real Groundwater: Effects of Water Chemistry. Ind Eng Chem Res 52:9343-9350. doi: 10.1021/ie400165a

Li X, Elliott DW, Zhang W (2006) Zero-Valent Iron Nanoparticles for Abatement of Environmental Pollutants: Materials and Engineering Aspects. Crit Rev Solid State Mater Sci 31:111-122. doi: 10.1080/10408430601057611

Liu Y, Lowry G V. (2006) Effect of Particle Age (Fe0 Content) and Solution pH On NZVI Reactivity: H2 Evolution and TCE Dechlorination. Environ Sci Technol 40:6085-6090. doi: 10.1021/es060685o

Liu Y, Phenrat T, Lowry G V (2007) Effect of TCE Concentration and Dissolved Groundwater Solutes on NZVI-Promoted TCE Dechlorination and H2 Evolution. Environ Sci Technol 41:7881-7887. doi: 10.1021/es0711967

Mackenzie PD, Horney DP, Sivavec TM (1999) Mineral precipitation and porosity losses in granular iron columns. J Hazard Mater 68:1-17. doi: http://dx.doi.org/10.1016/S03043894(99)00029-1

McIntyre T (2003) Phytoremediation of Heavy Metals from Soils BT - Phytoremediation. In: Tsao DT (ed) Advances in Biochemical Engineering/Biotechnology. Springer Berlin Heidelberg, Berlin, Heidelberg, pp 97-123

McKnight US, Funder SG, Rasmussen JJ, et al (2010) An integrated model for assessing the risk of TCE groundwater contamination to human receptors and surface water ecosystems. Ecol Eng 36:1126-1137. http://dx.doi.org/10.1016/j.ecoleng.2010.01.004

Mines PD, Byun J, Hwang Y, et al (2016) Nanoporous networks as effective stabilisation matrices for nanoscale zero-valent iron and groundwater pollutant removal. J Mater Chem A 4:632-639. doi: 10.1039/C5TA05025A

Nadagouda MN, Castle AB, Murdock RC, et al (2010) In vitro biocompatibility of nanoscale zerovalent iron particles (NZVI) synthesized using tea polyphenols. Green Chem 12:114-122. doi: 10.1039/B921203P

Nurmi JT, Tratnyek PG (2008) Electrochemical studies of packed iron powder electrodes: Effects of common constituents of natural waters on corrosion potential. Corros Sci 50:144-154. doi: http://dx.doi.org/10.1016/j.corsci.2007.06.016 
O’Carroll D, Sleep B, Krol M, et al (2013) Nanoscale zero valent iron and bimetallic particles for contaminated site remediation. Adv Water Resour 51:104-122. doi: http://dx.doi.org/10.1016/j.advwatres.2012.02.005

Panagos P, Van Liedekerke M, Yigini Y, Montanarella L (2013) Contaminated Sites in Europe: Review of the Current Situation Based on Data Collected through a European Network. J Environ Public Health 11 pages. doi: 10.1155/2013/158764

Prokop G, Schamann M, Edelgaard I, Gentile AR (2000) Management of contaminated sites in Western Europe. European Environment Agency, Copenhagen, Denmark

Ryu A, Jeong S-W, Jang A, Choi H (2011) Reduction of highly concentrated nitrate using nanoscale zero-valent iron: Effects of aggregation and catalyst on reactivity. Appl Catal B Environ 105:128-135. doi: http://dx.doi.org/10.1016/j.apcatb.2011.04.002

Shi Z, Fan D, Johnson RL, et al (2015) Methods for characterizing the fate and effects of nano zerovalent iron during groundwater remediation. J Contam Hydrol 181:17-35. doi: http://dx.doi.org/10.1016/j.jconhyd.2015.03.004

Squillace PJ, Thurman EM, Furlong ET (1993) Groundwater as a nonpoint source of atrazine and deethylatrazine in a river during base flow conditions. Water Resour Res 29:17191729. doi: 10.1029/93WR00290

Theron J, Walker JA, Cloete TE (2008) Nanotechnology and Water Treatment: Applications and Emerging Opportunities. Crit Rev Microbiol 34:43-69. doi: 10.1080/10408410701710442

Tosco T, Petrangeli Papini M, Cruz Viggi C, Sethi R (2014) Nanoscale zerovalent iron particles for groundwater remediation: a review. J Clean Prod 77:10-21. doi: 10.1016/j.jclepro.2013.12.026

Wang Q, Snyder S, Kim J, Choi H (2009) Aqueous Ethanol modified Nanoscale Zerovalent Iron in Bromate Reduction: Synthesis, Characterization, and Reactivity. Environ Sci Technol 43:3292-3299. doi: 10.1021/es803540b

Wang W, Jin Z, Li T, et al (2006) Preparation of spherical iron nanoclusters in ethanol-water solution for nitrate removal. Chemosphere 65:1396-404. doi: 10.1016/j.chemosphere.2006.03.075

Zhang XL, Tao S, Liu WX, et al (2005) Source Diagnostics of Polycyclic Aromatic Hydrocarbons Based on Species Ratios: A Multimedia Approach. Environ Sci Technol 39:9109-9114. doi: 10.1021/es0513741

Zou Y, Wang X, Khan A, et al (2016) Environmental Remediation and Application of Nanoscale Zero-Valent Iron and Its Composites for the Removal of Heavy Metal Ions: A Review. Environ Sci Technol 50:7290-7304. doi: 10.1021/acs.est.6b01897 